\title{
PRIORITY AREAS FOR DEVELOPMENT OF AGRICULTURE AT THE PRESENT STAGE OF SCIENTIFIC AND TECHNICAL PROGRESS
}

\author{
АНАЛИЗ ПРИОРИТЕТНЫХ НАПРАВЛЕНИЙ РАЗВИТИЯ ЗЕМЛЕДЕЛИЯ \\ НА СОВРЕМЕННОМ ЭТАПЕ НАУЧНО-ТЕХНИЧЕСКОГО ПРОГРЕССА
}

\author{
V. Lobkov, Doctor of Agricultural Sciences \\ В.Т. Лобков, доктор сельскохозяйственных наук \\ S. Plygun, Candidate of Agricultural Sciences \\ С.А. Плыгун, кандидат сельскохозяйственных наук \\ Orel State Agrarian University, Orel City, Russia \\ Орловский государственный аграрный университет, г. Орёл, Россия \\ Phone: +7 (4862) 45-40-37, E-mail: borpli@rambler.ru
}

Received February 9, 2012

\begin{abstract}
Discussed topical issues of modern agricultural science in the direction of biological function of agricultural production. Identified priority areas for new and improved farming systems, a system of expanded reproduction of soil fertility and the formation of a balanced eco-system of agricultural production.

\section{АННОТАЦИЯ}

Рассмотрены актуальные вопросы развития современной земледельческой науки по направлению биологизации сельскохозяйственного производства. Выделены новые и приоритетные направления совершенствования систем земледелия, системы расширенного воспроизводства почвенного плодородия и формирования эколого-сбалансированной системы производства сельскохозяйственной продукции.
\end{abstract}

\section{KEY WORDS}

System of agriculture; Biological function; Crop rotation; Soil biological activity; Reproduction; Soil fertility.

КЛЮЧЕВЫЕ СЛОВА

Система земледелия; Биологизачия; Севооборот; Биологическая активность почвы; Воспроизводство; Почвенное плодородие.

Для современного этапа развития земледелия характерно использование большого количества новых технологий с различным уровнем интенсивности. При этом вектор развития этих технологий определился на основе использования новых технических средств и элементов прецизионного земледелия.

Прецизионное (точное) земледелие или управление локальными земельными ресурсами представляет собой технологии использования земель на уровне внутриполевой дифференциации.
Если адаптивно-ландшафтные системы земледелия основаны на рациональном использовании земель на уровне полей севооборотов, то технологии точного земледелия применяются к конкретным участкам внутри полей в соответствии с их почвенноэкологическими условиями.

В последние 20 лет данное направление становится одной из доминирующих тенденций в мировом земледелии. Периодически проводятся конференции по вопросам внутриполевой пестроты плодородия почвы и 
прецизионного земледелия. На английском языке выходит специализированный журнал «Прецизионное земледелие».

Особое развитие технологии прецизионного земледелия получили в США. Практически во всех ведущих университетах этой страны имеются группы по исследованию вопросов прецизионного земледелия. Более 10 лет назад президент США обозначил прецизионное земледелие как главный приоритет в развитии национальной экономики.

Налажен выпуск специального оборудования несколькими международными корпорациями с центрами базирования в США, Дании, Англии, Франции, Финляндии. Широкомасштабные исследования проводятся также в странах Центральной Азии и в Китае. Применение технологий прецизионного земледелия позволяет обеспечить экономию ресурсов на 20-30\%, существенно повысить эффективность и экологические показатели использования земельных ресурсов.

По нашим данным внутриполевая пестрота почвенного покрова приводит к тому, что в условиях Орловщины колебания урожаев в пределах одного поля достигает 40-60\%. Исследования, проведенные на агрополигоне Всероссийского научно-исследовательского института агрохимии им. Д.Н. Прянишникова показали, что на участке площадью 4 га, разделенном на 400 равновеликих (10x10 м) делянок, содержание гумуса по отдельным делянкам колебалось от 1,15 до $3,1 \%$, то есть по принятой градации, от очень низкой до высокой обеспеченности. Внутриполевая пестрота показателей плодородия почвы возрастает в условиях склонового рельефа: по данным Всероссийского ВНИИ земледелия и защиты почв от эрозии диапазон варьирования равновесной плотности сложения пахотного горизонта превышает 40\%, при этом на склонах даже небольшой крутизны контрастность структуры почвенного покрова существенно возрастает.

Пестрота почвенного покрова приводит к существенным различиям в интенсивности роста и развития растений на различных участках поля. Фенофазы наступают в различное время. Это приводит к тому, что при уборке урожая в бункера попадает продукция с различными технологическими свойствами, в результате чего требуются большие затраты на сортировку и осуществление других прие- мов по доведению полученной продукции до однородного состояния.

Как следует из приведенного выше, в Российском земледелии имеются все предпосылки для использования элементов точного земледелия. При этом следует отметить, что даже в странах с высоким уровнем технического оснащения прецизионное земледелие имеет очень ограниченное практическое распространение. Речь в данном случае идет больше о направлении научных исследований. В связи с этим, на наш взгляд, правильнее ставить задачу повышения уровня технического обеспечения использования интенсивных технологий через внедрение элементов глобального позиционирования в земледелии, использовании картирования полей по данным аэрокосмического мониторинга, использования техники, оборудованной системами параллельного вождения, сенсорными устройствами и т.п.

При этом помимо новых приоритетов не меньшее, а зачастую и большее значение имеет соблюдение известных классических принципов. Прежде всего, это использование эколого-ландшафтного подхода в системах земледелия, который позволяет реализовывать дополнительные возможности для производства экологически чистой продукции и предотвращения деградации почвенного покрова.

Особое внимание уделяется вопросам предотвращения почвоутомления на основе оптимизации севооборотов. Исследования в ряде хозяйств Орловской, а также Липецкой, Воронежской и Курской областей показали, что устойчивость почв к утомлению уменьшилась. Отмечены пороговые значения фитотоксичности почв. Все это - следствие пренебрежительного отношения к севооборотным правилам, имеющее место в современном земледелии. Разработанная к настоящему времени методическая и нормативная основа для автоматизированного проектирования севооборотов в системах земледелия сельскохозяйственных предприятий и организаций Орловской области дает возможность оптимизировать севооборотный фактор.

Приоритетными являются вопросы разработки системы воспроизводства плодородия. Экономически и экологически целесообразным является их решение на основе повышения экологической емкости агроэкосистем и оптимизации биологической активности 
почвы. Кафедрой земледелия Орёл ГАУ разработаны новые способы, защищенные патентами РФ, по предотвращению негативных явлений вследствие контакта растительных остатков с семенами культурных растений, по повышению эффективности использования сидерации, а также новые удобрительные средства.

При оптимизации технологий обработки почвы следует учитывать достоинства и недостатки каждой группы приемов и способов. Имеет место следующая особенность: чем ближе данный вид культурного растения к диким формам, тем меньше его реакция на дифференциацию пахотного слоя (многолетние травы, злаки). Чем более в результате селекционной работы данная культура отдалилась от диких форм, тем больше ее потребности в гомогенном по плодородию пахотном слое. В связи с этим целесообразна дифференцированная обработка почвы в севооборотах. Наметившиеся тенденции к всеобщей минимализации обработки могут привести к значительным почвенно-экологическим последствиям.

С целью разработки направлений совершенствования технологий обработки почвы на основе использования современных почвообрабатывающих и посевных орудий на кафедре земледелия в 2009 г. был заложен многофакторный опыт. Место проведения исследований - НОПЦ «Интеграция». На темносерой лесной почве исследуются почвенноэкологические последствия и агроэкономическая эффективность сочетаний приемов основной и предпосевной обработки почвы, использования различных посевных орудий. Полученные первые результаты подтверждают имеющиеся данные о возможности применения минимальных технологий обработки почвы в условиях интенсивного применения химических средств защиты растений. Особенно повышается значение энергосберегающих технологий обработки почвы в условиях засухи.

Принципиальным в этих условиях с является то, что сложившиеся в учении об обработке почвы классические представления нуждаются в серьезной дополнительной теоретической и экспериментальной доработке. Связано это с тем, что разработанные подходы к основной, предпосевной обработке почвы и технологиям посева в современных ус- ловиях зачастую неприемлемы. Мощные сельскохозяйственные движители и многофункциональные почвообрабатывающие посевные орудия, огромные возможности химических способов борьбы с вредоносными объектами, внесение больших доз удобрений и мелиорантов создают условия для применения принципиально иных технологических схем, базирующихся на новых теоретических принципах.

При этом, не следует забывать и о больших возможностях биологизированных систем земледелия. Реализация концепции биологизации земледелия связана с решением ряда задач и не может быть достигнута одномоментно. На первых этапах должны решаться те вопросы, которые не требуют существенной перестройки технологических процессов и организации производства. В первую очередь полевое травосеяние. Наряду с многолетними травами серьезным фактором биологизации стали зернобобовые культуры, особенно новые сорта гороха. В результате появляется возможность замены части азота минеральных удобрений на азот биологический.

Реализация концепции биологизации земледелия позволяет уменьшить остроту проблемы защиты почв от эрозии. В свое время в нашей области была разработана программа увеличения ежегодных посадок леса до 4-5 тысяч гектаров. Составной частью экологического каркаса стал созданный Постановлением Правительства Российской Федерации № 6 от 9.01.1994 г. Национальный парк «Орловское Полесье».

Биологизация земледелия позволяет нашей области снизить энергозатраты примерно на 4700 тыс. гДж, что эквивалентно примерно 25 тыс. тонн дизельного топлива.

В настоящее время вопросы воспроизводства почвенного плодородия являются особенно актуальными. Связано это как с экономическими, так и с эколого-ресурсными условиями исчерпаемость энергетических и минеральных ресурсов, угроза экологического дисбаланса в биосфере, масштабные антропогенные изменения, что сделало очевидной актуальность вопроса о перспективах развития земледелия, о роли земледелия в решении стратегических вопросов развития агропромышленного блока. 
Зачастую, когда говорят о биологизации земледелия, то имеют в виду переход всей земледельческой отрасли на путь биологического развития. Однако вряд ли такой подход является обоснованным и правильным. Земледелие должно быть биологизировано в том смысле, что в каждой системе земледелия, независимо от формы хозяйствования, должны быть максимально использованы все биологические факторы формирования урожая сельскохозяйственных культур и воспроизводства почвенного плодородия. Кроме того, внедрению элементов биологизации должна предшествовать качественная экспертная оценка внедрения биологических систем земледелия. Только в этом случае биологизация будет работать на улучшение использования земли, повышения эффективности небиологических факторов и устранения негативных последствий их использования.

Принципиальный элемент биологизации земледелия севооборот. Связано это с тем, что севооборот является, пожалуй, единственным агротехническим элементом в системе земледелия, действие которого основано на природных механизмах. В отличие от мероприятий по обработке почв, удобрений и химической защиты растений его использование не связано с существенными энергетическими и ресурсными затратами.

Севооборот является фактором более полного использования экологических ресурсов продуктивности сельскохозяйственных культур света, тепла, влаги, естественного плодородия почв, находящихся на территории агроландшафта. Правильное размещение культур, их оптимальное чередование являются основой его высокопродуктивного функционирования и устойчивости.

Агроландшафтный подход к разработке севооборотов находит широкое применение через дифференцированное использование пашни. С целью рационального использование и предотвращения смыва почв на стадии землеустройства пахотные земли разделяют на категории интенсивного, умеренного и ограниченного использования. Культуры с большой почвозащитной способностью в гораздо меньшей степени снижают урожайность на эродированных почвах. Поэтому дифференцированное использование пашни позволяет без дополнительных затрат повысить её продуктивность на 10-15\% и уменьшить эрозию минимум в два раза.

Особенности ландшафта в настоящее время учитываются далеко не полностью. Главным критерием при разделении пашни на категории по интенсивности использования является степень эрозионной опасности, оцениваемая по величине уклона поверхности. Последняя, правда, корректируется для разных типов почв. Однако игнорируется генезис, возраст и морфология рельефа, тип водного режима, минерализация фунтовых вод, особенности стока и смыва на отдельных элементах рельефа в связи с их взаимным расположением.

Экологизация севооборотов должна осуществляться на основе оптимизации состава и чередования культур, насыщения севооборотов культурами-почвоулучшателями. Травы являются уникальными по своему действию на почву культурами, о чем писали Докучаев, Костычев, Вильямс, Каштанов. Оструктуривающее действие, способность обогащать пахотный слой азотом, кальцием, фитосанитарное значение обуславливают их особую роль в решении вопроса экологизации севооборотов.

Исследованиями установлено, что использование преимущественно биологических факторов воспроизводства плодородия почвы положительно сказывается на общем уровне её биологической активности (Лобков, 1998). При этом изменение относительного показателя биогенности почвы, отражающего агрономическую ценность формирующейся в почве ассоциации микроорганизмов, носит сходный с общей биогенностью характер. Использование сидератов и побочной продукции на удобрение обуславливает одинаковое соотношение бактериальной и грибной микрофлоры, при их взаимодействии и под влиянием навоза данный показатель изменяется в сторону увеличения.

Плодосменный севооборот отличается от зернопаропропашного, прежде всего, разнообразием чередующихся в неё культур: если первый составляют культуры, относящиеся к двум ботаническим семействам (Роасеае и Chenopodiaceae), то в состав второго входят культурные растения из трёх семейств (Legumminoceae, Poaceae и Chenopodiaceae), в том числе и многолетние травы. Наиболее уязвимым в экологическом плане элементов в 
севооборотах является паровое звено. В структуре использования пашни многих хозяйств доля парового клина выросла до 10\% и более. Связано это с тем, что в современных экономических условиях в паровом поле можно эффективно проводить агротехнические мероприятия по повышению плодородия почвы и оздоровлению фитосанитарной обстановки без значительных затрат на приобретение химических средств и специальной техники. Вместе с тем, явно просматривается тенденция к упрощению вопросов повышения эффективности парового клина на основе его оптимизации в структуре использования пашни.

Паровое поле это особое поле, которое не участвует в создании сельскохозяйственной продукции в течение года, но оказывающее большое влияние на все агрофизические показатели, на воздушный, тепловой и питательный режимы. Кроме различных трав, парозанимающей культурой могут быть и пропашные ранний картофель, кукуруза, сорго и др. Пары оказывают сложное кумулятивное действие на почву. Это проявляется в их длительном последействии в течение 2-3 лет. Наиболее продуктивными являются занятые пары, однако, они сложнее по технологии, и их освоение требует высокого уровня развития хозяйства и более совершенной постановки агрономической работы.

При несвоевременной обработке занятых паров верхний слой почвы пересыхает, теряет физическую спелость, при обработке дает глыбы и делает невозможным хорошую разделку почвы, благоприятную для накопления влаги, микробиологических процессов и роста растений. Именно с этим связана, зачастую, его невысокая эффективность в реальных производственных условиях.

Применительно к условиям Центральной России общая площадь парового клина должна определяться следующими обстоятельствами:

- обеспечение условий для проведения комплексного агрохимического улучшения состояния почвенного покрова;

- необходимостью проведения кардинальных истребительных мер в отношении злостных многолетних сорняков;

- обеспечение условий получения высококачественного зерна озимой пшеницы,
- рельефными условиями (севообороты с паровыми полями должны размещаться на участках, величина уклона поверхности которых не превышает $2^{\circ}$ ).

При оптимизации структуры парового клина следует иметь в виду общие принципы использования пашни в агроландшафтах на эколого-экономических принципах, суть которых заключается в оптимизации соотношения между экономическими интересами и ограничениями по воспроизводству почвенного плодородия. В целом следует рекомендовать площадь парового клина до 8-10\% в структуре посевных площадей на темно-серых лесных и черноземных почвах.

Также особого внимания требуют поля как однолетних, так и многолетних бобовых культур. Их посевы должны рассматриваться не только в плане получения основной продукции, но и как «цеха» для фиксации азота атмосферы. На полях бобовых в максимальной степени должны использоваться все приёмы, способствующие не только получению высокой продуктивности, но и интенсифицирующие процессы симбиотической азотфиксации, т.е. должен быть отработан и внедряться комплекс мероприятий, позволяющий иметь в почве максимум биологического азота.

В целом, экологический аспект совершенствования севооборотного фактора подразумевает разработку севооборотов с комплексом мероприятий, обеспечивающим практически бесперебойное вступление в почву фитомассы в виде нетоварной части урожая, сидератов, органических удобрений. Внедрение такого подхода к созданию севооборотов позволит внести весомый вклад в решение проблемы сохранения плодородия почв для нынешнего и будущих поколений.

Для формирования высокоэффективных и экологически сбалансированных технологий производства сельскохозяйственной продукции, отвечающих всем требованиям современного производства, необходимо не только использование последних достижений научно-технического прогресса (технических разработок и решений, замкнутых технологических циклов), но и рациональное, ресурсосберегающее, эколого-ориентированное планирование хозяйственной деятельности.

В Орловской области имеется много примеров использования факторов ресурсос- 
бережения хозяйствах за счет применения новых технологий и рационального использования природных ресурсов. Одно из них - ЗАО «Луганское» Должанского района ведет растениеводство при минимальном применении средств химизации. Отработанная к настоящему времени модель биологизированного земледелия ориентирована на преимущественное использование внутрихозяйственных биологических факторов. Высокая экономическая эффективность производства, обеспеченная за счет замены антропогенных ресурсов более дешевыми биологическими, позволили ЗАО «Луганское» придти к такому финансовому состоянию, которое позволяет ему поддерживать нормальные экономические взаимоотношения со своими деловыми партнерами, не иметь долгов перед бюджетом и внебюджетными фондами и иметь средства для расширенного воспроизводства.

При разработке системы земледелия ЗАО АПК «Юность» была принята модель, в которой эффективность интенсивных технологий повышалась бы за счет применения способов интенсификации биологических факторов.
Основу ресурсосберегающих технологий здесь составляют нулевая обработка с использованием стерневых сеялок Amazone; поверхностная обработка почвы орудиями KOS$3,5 \mathrm{C}$; сочетание удобрения соломой с сидерацией. Ресурсный потенциал предприятия сконцентрирован на повышении эффективности растениеводческой отрасли. Экономику агрофирмы формируют несколько основных видов растениеводческой продукции: озимые зерновые культуры, подсолнечник и рапс, пользующиеся устойчивым спросом на рынке сельскохозяйственной продукции. Благодаря внедрению современных наукоемких технологий и высокопродуктивных сортов, как отечественной, так и зарубежной селекции, уровень рентабельности производства и переработки составляет 600-700\%. Урожайность озимой пшеницы, достигает 7,0 т/га.

Таким образом, сочетание новых технологий в земледелии с классическими приоритетами позволяет успешно решать задачи ресурсосбережения и повышения продуктивности пашни.

\section{БИБЛИОГРАФИЯ}

Баздырев, Г.И. Фитосанитарное состояние почвы в условиях интенсификации земледелия / Г.И. Баздырев // Известия TCXA. - 1983. - № 3. - C. 28-39.

Барановский, И.Н. Влияние сорняков на плодородие почвы и урожайность овса / И.Н. Барановский, Н.В. Лукьянов // Защита и карантин растений. - 2005. - № 11. - C. 32

Гармашов, В.М. Засоренность посевов при различных способах обработки почвы в зернопропашном севообороте / B.M. Гармашов, А.Ф. Витер // Земледелие. 2008. - № 5. - C. 37-38.

Гилис, М.Б. Влияние локального внесения удобрений на рост корней и прикорневую микрофлору. - Способы внесения удобрений / М.Б. Гилис. - Науч. Тр. ВАСХНИЛ. - 1976. - С. 41-46.

Груздев, Г.С. Влияние минеральных удобрений на сорняки в посевах яровых зерновых культур / Г.С. Груздев, В.А. Сатаров // Химия в сельском хозяйстве. - 1969. № 12. - C. 8-9.
Информационный бюллетень «Ведение государственного мониторинга состояния недр территории Орловской области» за 2008 год - Орел, 2009, Выпуск 14. $245 \mathrm{c}$.

Информационный бюллетень «Ведение государственного мониторинга состояния недр территории Орловской области» за 2009 год - Орел, 2010. - Выпуск 15. $256 \mathrm{c}$

Котяк, П.А. Влияние систем обработки, удобрений и гербицидов на токсичность почвы и урожайность полевых культур в условиях разных видов агроландшафтов / П.А. Котяк, Е.В. Чебыкина, А.М. Труфанов // Сборник научных трудов 30юбилейной всероссийской научнопрактической конференции. - Технологические проблемы сельскохозяйственного производства: Ярославль. - 2007. C. 75-84.

Кочевых, М.Ю. Изменение видового состава и структуры сорного компонента агрофитоценоза в посеве озимой тритикале под действием разных систем обработки 
почвы, удобрений и гербицидов / М.Ю. Кочевых, В.И. Смирнова // Сборник научных трудов 30-юбилейной всероссийской научно-практической конференции. - Технологические проблемы сельскохозяйственного производства: Ярославль. 2007. - C. 84-88.

Ладонин В.Ф. Комплексное применение гербицидов и удобрений в интенсивном земледелии / В.Ф. Ладонин, А.М. Алиев. - М.: Агропромиздат, 1991. - 269 с.

Ларина, Г.Е. Сорные и культурные растения как консорбенты агрофитоценоза / Г.Е. Ларина, Л.Д. Протасова // Агро XXI. 2007. - № 4-6. - С. 34-36.

Лопоносова, Н.В. Эффективность поверхностно-отвальной обработки дерновоподзолистой почвы в современном земледелии / Н.В. Лопоносова // Совершенствование технологий возделывания сельскохозяйственных культур. - Сборник научных трудов: Ярославль. - 2001. - C. 12-24.

Макаров, И.П. Минимализация обработки почвы / И.П. Макаров. - М.: Колос, 1984. - C. 24.
Сафонов, А.Ф. Урожайность яровых зерновых и плодородие дерново-подзолистой почвы при длительном применении удобрений и известкования в бессменных посевах и севообороте / А.Ф. Сафонов, А.А. Алферов, М.А. Золотарёв // Известия ТСХА. - 2001. - № 4. - С. 30-40.

Смирнов, Б.А. Эффективность системы разноглубинной обработки на дерновоподзолистой почве избыточного увлажнения / Б.А. Смирнов, С.В. Щукин // Известия ТСХА. - 2005. - № 1. - С. 34-43.

Смирнова, В.И. Действие разных по интенсивности систем обработки и удобрений на засорённость посевов и биологическую активность почвы / В.И. Смирнова, Е.В. Чебыкина, М.А. Кощеев // Совершенствование технологий возделывания сельскохозяйственных культур: Материалы межвузовской научнометодической конференции: Ярославль, 2000. - C. 91-96.

Sato, K. A study on environmental externalities of agriculture and its cost allocation problem / K. Sato // Mem. Graduate School Agr. Hokkaido Univ. - 2000. - Vol. 23. - № 2. P. 61-118. 